\title{
Effect of Beta - Blockers on Insulin Resistance in Patients with Hypertension and Metabolic Syndrome after 6 Months of Treatment
}

\author{
Yuriy Sirenko ${ }^{1 *}$, Oksana Rekovets ${ }^{2}$, Olena Torbas ${ }^{3}$, Sergey Savitskiy ${ }^{4}$ and Evgenia Pavlyuk ${ }^{5}$
}

\author{
${ }^{1}$ Professor, Head of the Department of Symptomatic Arterial Hypertension "State Institution "National scientific center "The M.D. Strazhesko Institute \\ of Cardiology" AMS Ukraine.
}
${ }^{2}$ Senior research assistant of the Department of Symptomatic Arterial Hypertension "State Institution "National scientific center "The M.D. Strazhesko Institute of Cardiology" AMS Ukraine. ${ }^{3}$ Research assistant of the Department of Symptomatic Arterial Hypertension "State Institution "National scientific center "The M.D. Strazhesko
Institute of Cardiology" AMS Ukraine.

${ }^{4}$ Professor Department of the Radioisotope "State Institution "National scientific center "The M.D. Strazhesko Institute of Cardiology" AMS Ukraine.

${ }^{5}$ Research assistant department of Symptomatic Arterial Hypertension "State Institution "National scientific center "The M.D. Strazhesko Institute of Cardiology" AMS Ukraine.

Received: April 03, 2017;Accepted: April 15, 2017; Published: May 05, 2017

*Corresponding author: Dr. Yuriy Sirenko, MD, PhD, Prof. Head of Department of Symptomatic Arterial Hypertension, Institute of cardiology, Kiev, Ukraine; Tel: +380958424521;E-mail: sirenkoyu@gmail.com

\begin{abstract}
Background

For years the use of beta-blockers in patients with metabolic syndrome has been limited due to the negative impact of non-selective beta - blockers on carbohydrate and lipid metabolism.

Aim

We studied antihypertensive therapy with different beta - blockers over 6 months on the impact on insulin resistance, lipid metabolism and blood pressure in patients with mild to moderate hypertension and metabolic syndrome.

\section{Materials and Methods}

Participants in this study came from a single clinic in Kiev, Ukraine attending a specialized hypertension clinic. This report includes 131 patients with mild to moderate hypertension and metabolic syndrome according to ATP III criteria without diabetes. There were 71 (54\%) males and 60 females. All patients had office and ambulatory blood pressure measurements, fasting blood glucose and lipid levels. Glucose and insulin levels were assessed during a glucose tolerance test (PGTT) at baseline and after 6 months. The HOMA index was calculated. For 7 days before all medications was stopped. Hydrochlorothiazide was added if needed for BP control.
\end{abstract}

\section{Results}

The mean follow-up $-6.30 \pm 0.60$ months. The mean age $-49.49 \pm 1.05$ years. The body weight $-93.74 \pm 1.21 \mathrm{~kg}$. The body mass index (BMI) $-32.05 \pm 0.35 \mathrm{~kg} / \mathrm{m} 2$ and was not changed during 6 months. Baseline office SBP and DBP were $154.21 \pm 0.71$ and $87.20 \pm 0.73 \mathrm{mmhg}$ accordingly. The baseline HR $-71.90 \pm 0.62$ beats/min. Mean SBP/DBP24 $-135.20 \pm 1.13 \mathrm{mmhg} / 79.27 \pm 0.87 \mathrm{mmhg}$. HR24 $-72.28 \pm 0.89$ beats/ min. During treatment with atenolol, carvedilol, bisoprolol and nebivolol mean SBP/DBP24 reduction did not differ between the groups: 16.86 , $15.40,16.26$ and $17.00 \mathrm{mmhg}$ respectively ( $\mathrm{p}<0.05$ for all values) and $10.67,9.00,12.72$ and $10.03 \mathrm{mmhg}$ respectively ( $\mathrm{p}<0.05$ for all values) and significantly decreased HR24 4.00, 3.92, 3.82 and 3.54 beats/min respectively ( $<<0,05$ for all). Glucose levels in the atenolol group increased at all three points of PGTT. Increased fasting insulin level is a sign of the progression of insulin resistance in group of atenolol. The percentage of patients with identified insulin resistance (HOMA $>3$ ) increased from $34.4 \%$ to $71.9 \%(\mathrm{p}<0.05)$. According to PGTT Score there were $6(18.7 \%)$ cases of onset diabetes. Carvedilol therapy contributed to a significant, reduction in fasting insulin. Fasting insulin decreased by $22.8 \%$ ( $p<0.05$ ), HOMA index decreased by $21.7 \%(\mathrm{p}<0.05)$, and serum glucose did not change significantly. The percentage of patients whose HOMA index $>=3$ decreased from $31.3 \%$ to $18.8 \%$. In the carvedilol group, there were 2 with onset diabetes (6.3\%). Bisoprolol significantly decreased HOMA index by $17.4 \%$ (p $<0.05)$, fasting insulin by $10.7 \%(\mathrm{p}<0.05)$, fasting glucose by $10 \%(\mathrm{p}<0.05)$. This group also demonstrated a positive trend toward HOMA index $>$ 3 (at baseline - $34.4 \%$ of patients at the end of the study - 12.5\%). There was also one case of the onset diabetes (3.2\%). In the nebivolol group the HOMA index decreased from $2.3 \pm 0.3$ to $1.76 \pm 0.1 \mathrm{mmol} / \mathrm{l}(\mathrm{p}<0.05)$, and fasting glucose decreased by $7.4 \%(\mathrm{p}<0.05)$; no cases of onset diabetes were recorded. The proportion of patients with manifest insulin resistance decreased from $34.3 \%$ to $2.9 \%(\mathrm{p}<0.05)$. Carvedilol treatment reduced levels of total cholesterol, TG, LDL cholesterol, VLDL cholesterol, IA; the level of HDL cholesterol was unchanged. TG levels decreased from $1.86 \pm$ 0.14 to $1.44 \pm 0.15 \mathrm{mmol} / \mathrm{l}(\mathrm{p}<0.05)$ and total cholesterol from $6.29 \pm 0.14$ to $5.86 \pm 0.25 \mathrm{mmol} / \mathrm{l}(\mathrm{p}>0,05)$. In the bisoprolol group TG decreased from $1.67 \pm 0.13 \mathrm{mmol} / \mathrm{l}$ to $1.58 \pm 0.15 \mathrm{mmol} / \mathrm{l},(\mathrm{p}>0,05)$ and total cholesterol decreased from $6.35 \pm 0.19 \mathrm{mmol} / \mathrm{l}$ to $5.78 \pm 0.18 \mathrm{mmol} / \mathrm{l}(\mathrm{p}=0,02)$. In 
the nebivolol group TG decreased from $1.74 \pm 0.15 \mathrm{mmol} / \mathrm{l}$ to $1.23 \pm 0.06 \mathrm{mmol} / \mathrm{l}$, and total cholesterol decreased from $6.12 \pm 0.25 \mathrm{mmol} / \mathrm{l}$ to 5.44 $\pm 0.20 \mathrm{mmol} / \mathrm{l}$ ( $\mathrm{p}<0.01$ for both values). In the atenolol group TG and total cholesterol changed not statistical significant. The levels of TG and VLDL in nebivolol group decreased from $29.4 \%$ and $25 \%$ respectively. Reduction of TG and VLDL in the carvedilol group was slightly lower about $21.0 \%$ and $12.5 \%$ respectively. Reduction of TG and VLDL in the Bisoprolol group was the lowest only $5.9 \%$ and $12.5 \%$, respectively.

\section{Conclusions}

This study showed that all four beta-blockers had similar BP lowering but different metabolic effects. There was a significant worsening of insulin resistance in patients receiving atenolol. Bisoprolol can be used as metabolically neutral drugs in patients with mild to moderate hypertension, clinical signs of metabolic syndrome and manifestations of insulin resistance without diabetes. Patients treated with nebivolol and carvedilol had a trend toward more improvement in insulin sensitivity and glucose tolerance. Nebivolol and carvedilol therapy significantly improved glycemic profile, which may improve prognosis. Nebivolol and carvedilol may be recommended as a drug of choice in patients with hypertension and metabolic syndrome with signs of impaired carbohydrate metabolism.

\section{Keywords}

arterial hypertension; nebivolol; carvedilol; bisoproprolol; atenolol; insulin resistance; HOMA; metabolic syndrome

\section{Background}

For years the use of beta-blockers in patients with metabolic syndrome has been limited due to the negative impact of non-selective beta - blockers on carbohydrate and lipid metabolism. Despite these possible adverse metabolic effects administration of beta -blockers in patients with type 2 diabetes had a similar impact on reducing the incidence of diabetic complications as the ACE inhibitor captopril (ref UKPDS 39).

Carvedilol, a third generation beta-blocker, is a nonselective drug with vasodylating facilities. This property (vasodylating effect) has differing effects on the metabolism of glucose and lipids. The highly selective beta -blocker bisoprolol may positively affect insulin sensitivity and reduces insulin resistance. Improvement of beta - blockers (Generation III) led to the creation of non-selective beta - blocker carvedilol, which has vasodylatating facilities and may be due to that affects the metabolism of glucose and lipids in another way. Some studies have shown that carvedilol increases insulin sensitivity, that reduces insulin resistance. This ability of carvedilol is associated with alpha 1 - adrenoblocade that may be particularly pronounced in combination with blockade of beta 2 - adrenergic receptors.

Nebivolol is a highly selective beta - blocker. Its selectivity is almost an order of magnitude greater than bisoprolol. In addition nebivolol has vasodilatating properties due to its impact on the production of NO, a major endogenous vasodilator $[2,5,19,21]$.

Our group studied antihypertensive therapy with different beta - blockers over 6 months on the impact on insulin resistance, lipid metabolism and blood pressure in patients with mild to moderate hypertension and metabolic syndrome.

\section{Materials and Methods}

Patients met the following inclusion criteria:

- $\quad$ Men and women aged 18 to 65 years;

- Mild to moderate arterial hypertension essential by WHO classification (1999) (International Society for the Study of hypertension) and Ukrainian Society of Cardiology (2004). One of the important conditions was the mean levels of blood pressure (BP) measured in the morning in a sitting position - office systolic blood pressure (SBP) was greater than $140 \mathrm{mmhg}$ and diastolic blood pressure (DBP) greater than $90 \mathrm{mmhg}$ at the end of the seven-day washout period;

- $\quad$ Antihypertensive drugs during the seven-day washout period were canceled;

- Metabolic syndrome according to ATP III criteria.

The study did not include patients with:

- $\quad$ Existing diabetes types I and II;

- $\quad$ Verified symptomatic hypertension;

- $\quad$ Level of office systolic (SBP) greater than $180 \mathrm{mmhg}$ or diastolic (DBP) blood pressure greater than $110 \mathrm{~mm} \mathrm{Hg}$ (Severe hypertension);

- Acute myocardial infarction or cerebrovascular accidents in history;

- $\quad$ Acute or chronic renal failure (serum creatinine levels more than $200 \mathrm{mmol} / \mathrm{l}$ )

- $\quad$ Decompensate liver disease (level of AST, ALT above 3 times upper limit of normal);

- Pregnancy or lactation;

- $\quad$ Heart failure;

- $\quad$ Clinical signs of coronary heart disease.

Participants in this study came from a single clinic in Kiev, Ukraine attending a specialized hypertension clinic. This report includes 131 patients with mild to moderate hypertension and metabolic syndrome according to ATP III criteria without diabetes (ref for ATII) [8]. There were 71 (54\%) males and 60 females. All patients had office and ambulatory blood pressure measurements, fasting blood glucose and lipid levels. Also glucose and insulin levels were assessed during a glucose tolerance test at baseline and after 6 months [18]. The HOMA index was calculated. Baseline data are found in (Table 1). For 7 days before all medications was stopped. Hydrochlorothiazide 
was added if needed for BP control. ABPM Meditech_04 every 15 minutes during day and 30 minutes at night was measurement BP method of doing 24 hour BP. This study was carried out with ethical approval from the study Institute of Cardiology, Kiev, Ukraine.

\begin{tabular}{|c|c|c|c|c|}
\hline & Atenolol & Carvedilol & Bisoprolol & Nebivolol \\
\hline $\mathbf{N}$ & 32 & 32 & 32 & 35 \\
\hline Age, year & $50.66 \pm 2.30$ & $47.6 \pm 2.30$ & $50.3 \pm 1.90$ & $49.4 \pm 2.00$ \\
\hline BMI, $\mathrm{kg} / \mathrm{m} 2$ & $32.76 \pm 0.99$ & $32.37 \pm 037$ & $32.20 \pm 0.37$ & $31.02 \pm 0.84$ \\
\hline Weight, kg & $96.61 \pm 2.46$ & $92.53 \pm 1.91$ & $93.25 \pm 1.86$ & $92.66 \pm 3.09$ \\
\hline WHR, units & $0.94 \pm 0.01$ & $0.92 \pm 0.01$ & $0.92 \pm 0.01$ & $0.94 \pm 0.01$ \\
\hline $\begin{array}{l}\text { Family history of } \\
\text { HT, } \%\end{array}$ & 74 & 77 & 73 & 75 \\
\hline $\begin{array}{l}\text { Office BP SBP, } \\
\text { mm Hg }\end{array}$ & $153.53 \pm 1.47$ & $153.40 \pm 1.30$ & $154.63 \pm 1.57$ & $155.14 \pm 1.40$ \\
\hline $\begin{array}{l}\text { Office BP DBP, } \\
\text { mmHg }\end{array}$ & $88.03 \pm 1.33$ & $87.00 \pm 1.79$ & $85.59 \pm 1.66$ & $88.06 \pm 1.06$ \\
\hline Heart rate, b.p.m. & $71.59 \pm 1.16$ & $72.44 \pm 1.33$ & $71.75 \pm 1.25$ & $71.83 \pm 1.17$ \\
\hline
\end{tabular}

The proportion of patients treated with mono-or combination therapy in groups of observation was the same.

Initial examination, clarification of criteria for inclusion in the study and the distribution of the patients (using envelopes) into three groups, depending on the intended antihypertensive therapy:

Group 1 - atenolol therapy (Tenolol, IPKA, India) 50 - $100 \mathrm{mg}$ daily in two divided doses.

Group 2 - carvedilol therapy (Talliton, “Egis”, Hungary) 25 - 50 mg daily in two divided doses.

Group 3 - bisoprolol therapy (Bisoprolol - ratiopharm, "Ratiopharm", Germany) 10 - 20 mg once daily.

Group 4 - patients administered nebivolol (Nebilet, "Berlin Chemie", Germany) 5 - 10 mg once daily.

When during the first month of treatment target levels of office blood pressure $(<140 / 90 \mathrm{~mm} \mathrm{Hg})$ were not achieved hydrochlorothiazide at a dose of $12.5 \mathrm{mg}$ once daily was added to the administered therapy. Repeated full examination was performed after 6 month at the end of observation.

In 1998 it was recommended by in 6's recommendations of the U.S. National Committee for diagnosis and treatment of hypertension tat the normal values of blood pressure are: for average daily SBP - $135 \mathrm{~mm} \mathrm{Hg}$, for average daily DBP - 85 mmhg. In 1999, experts from WHO and the International Society of Hypertension recommended to consider as a normal blood pressure an average daily SBP - $125 \mathrm{mmhg}$ and average daily DBP - $80 \mathrm{mmhg}$

Based on the data in creating a database system in SPSS. Statistical analysis of the results was performed using the analysis package in SPSS system and computer software package SPSS. 19. ANOVA to calculate the following parameters: the arithmetic mean value $-M$, the SD from the arithmetic mean value of $-m$; coefficient of reability $-\mathrm{p}$. The difference was considered reliable at a value of $\mathrm{p}<0.05$.

\section{Results}

We examined 131 patients. The mean follow-up was $6.30 \pm 0.60$ months. The mean age was $49.49 \pm 1.05$ years. The average body weight $-93.74 \pm 1.21 \mathrm{~kg}$. The Average body mass index (BMI) was $32.05 \pm 0.35 \mathrm{~kg} / \mathrm{m} 2$ and was not changed during 6 months. The waist/hip ratio of the whole group was $-0.93 \pm 0.01$ units. $74.8 \%$ of patients had burdened heredity in hypertension, and $30.5 \%$ - in diabetes mellitus. Average baseline office SBP and DBP were $154.21 \pm 0.71$ and $87.20 \pm 0.73 \mathrm{mmhg}$ accordingly. The average heart rate was $71.90 \pm 0.62$ beats $/ \mathrm{min}$. Mean ambulatory blood pressure monitoring (ABMP) was $135.20 \pm 1.13 \mathrm{mmhg}$ for SBP and $79.27 \pm 0.87 \mathrm{mmhg}$ for DBP. Average heart rate at ABMP was72.28 \pm 0.89 beats $/ \mathrm{min}$. Baseline date in each groups show in (Table 2).

\begin{tabular}{|l|l|l|l|}
\hline \multicolumn{3}{|c|}{ Table 2: Dynamics office BP (M $\pm \mathrm{m})$} \\
\hline Office BP & $\begin{array}{l}\text { Before } \\
\text { treatment }\end{array}$ & After treatment & Delta \\
\hline \multicolumn{4}{|c|}{ Atenolol, (n=32) } \\
\hline Office BP SBP, mm Hg & $\begin{array}{l}153.53 \pm \\
1.47\end{array}$ & $130.13 \pm 1.39^{*}$ & -23.41 \\
\hline Office BP DBP, mmHg & $88.03 \pm 1.33$ & $78.00 \pm 0.88^{*}$ & -10.03 \\
\hline Heart rate, b.p.m. & $71.59 \pm 1.16$ & $64.44 \pm 1.45^{*}$ & -7.16 \\
\hline \multicolumn{5}{|l|}{ Carvedilol, (n=32) } \\
\hline Office BP SBP, mm Hg & $\begin{array}{l}153.44 \pm \\
1.30\end{array}$ & $131.88 \pm 1.26^{*}$ & -21.56 \\
\hline Office BP DBP, mmHg & $87.03 \pm 1.79$ & $77.63 \pm 1.27^{*}$ & -9.41 \\
\hline Heart rate, b.p.m. & $72.44 \pm 1.33$ & $68.88 \pm 0.97^{*}$ & -3.56 \\
\hline \multicolumn{5}{|l|}{ Bisoprolol, (n=32) } \\
\hline Office BP SBP, mm Hg & $154.63 \pm$ & $133.28 \pm 1.43^{*}$ & -21.34 \\
\hline Office BP DBP, mmHg & $85.59 \pm 1.66$ & $76.25 \pm 1.29^{*}$ & -9.34 \\
\hline Heart rate, b.p.m. & $71.75 \pm 1.25$ & $65.19 \pm 0.91^{*}$ & -6.56 \\
\hline Office BP SBP, mm Hg & $155.14 \pm 1.40$ & $131.31 \pm 0.83^{*}$ & -23.83 \\
\hline Office BP DBP, mmHg & $88.06 \pm 1.06$ & $78.49 \pm 1.09^{*}$ & -9.57 \\
\hline Heart rate, b.p.m. & $71.83 \pm 1.23$ & $65.57 \pm 1.17^{*}$ & -6.26 \\
\hline & & \\
\hline & & \\
\hline
\end{tabular}


BP was equivalent in all four groups. Office BP decreased equally in all groups.

During treatment with atenolol, carvedilol, bisoprolol and nebivolol blood pressure reduction over 24 hours did not differ between the groups. There was a decrease in the average systolic pressure of $16.86,15.40,16.26$ and $17.00 \mathrm{~mm}$
Hg respectively ( $p<0.05$ for all values) and the average DBP decreased by $10.67,9.00,12.72$ and 10.03 mmhg respectively (p $<0.05$ for all values). (Figure 1, figure 2). Treatment with atenolol carvedilol, bisoprolol and nebivolol significantly decreased the average heart rate by $4.00,3.92,3.82$ and 3.54 beats / $\mathrm{min}$ respectively $(p<0,05$ for all).

\begin{tabular}{|c|c|c|c|c|}
\hline Before treatment & $\begin{array}{l}\text { Atenolol } \\
(n=32)\end{array}$ & $\begin{array}{l}\text { Carvedilol } \\
(n=32)\end{array}$ & Bisoprolol (n=32) & Nebivolol ( $n=35)$ \\
\hline 24SBP, mmHg & $136.33 \pm 2.40$ & $133.94 \pm \mathbf{1 . 7 9}$ & $134.67 \pm 2.50$ & $134.47 \pm 2.35$ \\
\hline 24DBP, mmHg & $80.75 \pm 2.01$ & $80.47 \pm 1.68$ & $77.76 \pm 1.89$ & $78.88 \pm 1.50$ \\
\hline $24 \mathrm{PP}, \mathrm{mmHg}$ & $57.56 \pm 2.11$ & $53.32 \pm \mathbf{1 . 6 6}$ & $56.24 \pm 1.71$ & $55.56 \pm 1.60$ \\
\hline 24HR,b.p.m. & $72.50 \pm 1.01$ & $72.04 \pm 1.02$ & $72.20 \pm 1.04$ & $73.31 \pm 1.05$ \\
\hline daySBP, mmHg & $141.50 \pm 2.32$ & $140.24 \pm 2.06$ & $139.04 \pm 2.71$ & $140.66 \pm 2.22$ \\
\hline Day DBP, mmHg & $84.94 \pm \mathbf{2 . 0 3}$ & $86.00 \pm 2.03$ & $83.78 \pm 2.02$ & $83.54 \pm 1.53$ \\
\hline dayPP, $\mathrm{mmHg}$ & $58.44 \pm 1.96$ & $54.10 \pm 1.71$ & $55.19 \pm 1.69$ & $56.86 \pm 1.73$ \\
\hline Day HR, b.p.m & $75.81 \pm 1.02$ & $76.72 \pm 2.05$ & $79.66 \pm 2.02$ & $75.24 \pm 1.05$ \\
\hline Night SBP, mmHg & $126.86 \pm 2.67$ & $124.20 \pm 1.91$ & $120.83 \pm 3.41$ & $124.54 \pm 2.86$ \\
\hline Night DBP, mmHg & $73.14 \pm 2.21$ & $71.84 \pm 1.47$ & $76.09 \pm 1.02$ & $69.94 \pm 1.93$ \\
\hline Night PP, mmHg & $55.67 \pm 2.37$ & $52.30 \pm 1.65$ & $65.59 \pm 2.81$ & $54.67 \pm 1.91$ \\
\hline Night HR, b.p.m & $64.56 \pm 1.06$ & $63.74 \pm 1.03$ & $64.31 \pm 1.05$ & $66.71 \pm 1.05$ \\
\hline
\end{tabular}

Figure 2: ABMP after treatment on groups

\begin{tabular}{|c|c|c|c|c|}
\hline After treatment & $\begin{array}{l}\text { Atenolol } \\
(\mathrm{n}=32)\end{array}$ & $\begin{array}{l}\text { Carvedilol } \\
(\mathrm{n}=32)\end{array}$ & Bisoprolol $(n=32)$ & Nebivolol $(n=35)$ \\
\hline 24SBP, mmHg & $119.46 \pm 1.90^{*}$ & $118.35 \pm 1.13 \#$ & $117.41 \pm 1.46 \$$ & $117.47 \pm 1.49 £$ \\
\hline 24DBP, mmHg & $70.07 \pm 1.37^{*}$ & $71.48 \pm \mathbf{1 . 2 3} \#$ & $65.03 \pm 3.11 \$$ & $68.85 \pm 1.05 £$ \\
\hline 24PP, mmHg & $49.65 \pm 1.60^{*}$ & 49.01士1.38\# & $45.28 \pm 2.25 \$$ & $48.68 \pm 1.18 £$ \\
\hline 24HR,b.p.m. & $68.51 \pm 1.05^{*}$ & $68.12 \pm 1.06 \#$ & $68.38 \pm 1.07 \$$ & $69.77 \pm 1.03 £$ \\
\hline DaySBP, mmHg & $123.76 \pm 2.02^{*}$ & $127.23 \pm \mathbf{1 . 1 5} \#$ & $124.11 \pm 1.86 \$$ & $121.17 \pm \mathbf{1 . 4 5 £}$ \\
\hline Day DBP, mmHg & $74.17 \pm 1.51^{*}$ & $77.82 \pm 1.37 \#$ & $74.63 \pm 1.71 \$$ & $72.40 \pm 1.19 €$ \\
\hline DayPP, mmHg & $50.46 \pm 1.59^{*}$ & 49.48 $\pm 1.33 \#$ & $49.52 \pm 1.33 \$$ & $48.63 \pm \mathbf{1 . 1 8 £}$ \\
\hline Day HR, b.p.m & $72.12 \pm 1.07^{*}$ & $73.70 \pm 1.11 \#$ & $74.14 \pm 1.10 \$$ & $73.14 \pm 1.15 €$ \\
\hline Night SBP, mmHg & $110.97 \pm 2.01^{*}$ & $111.65 \pm 1.51 \#$ & $107.10 \pm 1.68 \$$ & $111.11 \pm 1.89 \notin$ \\
\hline Night DBP, mmHg & $62.48 \pm 1.46^{*}$ & $63.16 \pm 1.32 \#$ & $61.44 \pm 1.39 \$$ & $62.20 \pm 1.13 £$ \\
\hline Night PP, mmHg & $48.49 \pm 1.55^{*}$ & $48.56 \pm 1.49 \#$ & $45.62 \pm \mathbf{1 . 4 2 \$}$ & $48.94 \pm \mathbf{1 . 3 4 £}$ \\
\hline Night HR, b.p.m & $62.02 \pm 1.20^{*}$ & $61.50 \pm 1.07 \#$ & $61.90 \pm 1.09 \$$ & $62.49 \pm 1.13 €$ \\
\hline \multicolumn{5}{|c|}{ \# - $\mathrm{p}<0.05$ between before and after treatment in atenolol group } \\
\hline \multicolumn{5}{|c|}{$\#$ - $\mathrm{p}<0.05$ between before and after treatment in carvedilol group } \\
\hline \multicolumn{5}{|c|}{$\$-\mathrm{p}<0.05$ between before and after treatment in Bisoprolol group } \\
\hline \multicolumn{5}{|c|}{$£-p<0.05$ between before and after treatment in nebivolol group } \\
\hline
\end{tabular}


Significant office blood pressure control $<<140 / 90$ mmhg) was achieved in $78.1 \%$ of patients in the atenolol group, $75 \%$ of patients in the carvedilol group, $81.3 \%$ in the bisoprolol group and $80 \%$ in the nebivolol group, $(p>0,05)=$ non significant between groups). Significant (ambulatory blood pressure control) (less than 125/80 $\mathrm{mm} \mathrm{Hg}$ ) was achieved in $71.9 \%$ in the atenolol group,in $62.5 \%$ of patients in the carvedilol group, in $78 \%$ of patients in the bisoprolol group and $74.3 \%$ in the nebivolol group ( $>0,05)=$ non - significant between groups).

Carvedilol treatment reduced levels of total cholesterol, triglycerides, LDL cholesterol, VLDL cholesterol, IA; the level of HDL cholesterol was unchanged. Triglyceride levels decreased from $1.86 \pm 0.14$ to $1.44 \pm 0.15 \mathrm{mmol} / \mathrm{l}(\mathrm{p}<0.05)$ and total serum cholesterol from $6.29 \pm 0.14$ to $5.86 \pm 0.25 \mathrm{mmol} / \mathrm{l}$ but not statistical significant (Table 3). In the bisoprolol treatment group triglyceride levels decreased from $1.67 \pm 0.13 \mathrm{mmol} / \mathrm{l}$ to $1.58 \pm$ $0.15 \mathrm{mmol} / \mathrm{l},(\mathrm{p}>0,05)$ and serum total cholesterol decreased from $6.35 \pm 0.19 \mathrm{mmol} / \mathrm{l}$ to $5.78 \pm 0.18 \mathrm{mmol} / \mathrm{l}(\mathrm{p}=0,02)$. In the nebivolol group triglyceride levels decreased from $1.74 \pm 0.15$ $\mathrm{mmol} / \mathrm{l}$ to $1.23 \pm 0.06 \mathrm{mmol} / \mathrm{l}$, and total cholesterol decreased from $6.12 \pm 0.25 \mathrm{mmol} / \mathrm{l}$ to $5.44 \pm 0.20 \mathrm{mmol} / \mathrm{l}$ ( $\mathrm{p}<0.01$ for both values). In the atenolol group TG and total cholesterol changed not statistical significant. The levels of TG and VLDL in nebivolol group decreased from $29.4 \%$ and $25 \%$ respectively. Reduction of these parameters in the carvedilol group was slightly lower about $21.0 \%$ and $12.5 \%$ respectively. Reduction of TG and VLDL in the bisoprolol group was the lowest only $5.9 \%$ and $12.5 \%$, respectively. (Table 3).

Table 3: Dynamics of lipid level during treatment in groups

\begin{tabular}{|c|c|c|c|c|c|c|c|c|}
\hline & \multicolumn{2}{|c|}{ Atenolol, $(n=32)$} & \multicolumn{2}{|c|}{ Carvedilol $(n=32)$} & \multicolumn{2}{|c|}{ Bisoprolol, $(n=32)$} & \multicolumn{2}{|c|}{ Nebivolol, $(n=35)$} \\
\hline & $\begin{array}{l}\text { Before } \\
\text { treatment }\end{array}$ & $\begin{array}{l}\text { After } \\
\text { treatment }\end{array}$ & $\begin{array}{l}\text { Before } \\
\text { treatment }\end{array}$ & $\begin{array}{l}\text { After } \\
\text { treatment }\end{array}$ & $\begin{array}{l}\text { Before } \\
\text { treatment }\end{array}$ & $\begin{array}{l}\text { After } \\
\text { treatment }\end{array}$ & $\begin{array}{l}\text { Before } \\
\text { treatment }\end{array}$ & $\begin{array}{l}\text { After } \\
\text { treatment }\end{array}$ \\
\hline $\begin{array}{l}\text { Total cholesterol, } \\
\mathrm{mmol} / \mathrm{l}\end{array}$ & $6.12 \pm 0.19$ & $6.17 \pm 0.15 \alpha$ & $6.29 \pm 0.14$ & $5.86 \pm \mathbf{0 . 2 5}$ & $6.35 \pm 0.19$ & $\begin{array}{l}5.78 \pm \\
0.18 \$ \mu\end{array}$ & $6.12 \pm 0.25$ & $5.44 \pm 0.20 €$ \\
\hline Triglycerides,mmol/l & $1.77 \pm 0.12$ & $2.09 \pm 0.21 \alpha$ & $1.86 \pm 0.14$ & $\begin{array}{l}1.44 \pm \\
0.15 \# \beta\end{array}$ & $1.67 \pm 0.13$ & $1.58 \pm 0.15$ & $1.74 \pm 0.15$ & $1.23 \pm 0.06 \boldsymbol{E}$ \\
\hline HD cholesterol,mmol/l & $1.18 \pm 0.04$ & $1.21 \pm 0.03$ & $1.17 \pm \mathbf{0 . 0 3}$ & $1.21 \pm 0.03$ & $1.28 \pm 0.04$ & $1.18 \pm 0.03 €$ & $1.20 \pm 0.03$ & $1.27 \pm \mathbf{0 . 0 2} \subseteq$ \\
\hline $\begin{array}{l}\text { LDL cholesterol, } \\
\mathrm{mmol} / \mathrm{l}\end{array}$ & $4.08 \pm 0.20$ & $4.01 \pm 0.15$ & $4.17 \pm \mathbf{0 . 1 6}$ & $3.99 \pm 0.23$ & $4.25 \pm 0.19$ & $3.88 \pm 0.17$ & $4.12 \pm 0.24$ & $3.61 \pm 0.19 \notin$ \\
\hline $\begin{array}{l}\text { VLDL cholesterol } \\
\mathrm{mmol} / \mathrm{l}\end{array}$ & $0.80 \pm 0.06$ & $0.94 \pm 0.10 \alpha$ & $0.82 \pm 0.05$ & $0.65 \pm \mathbf{0 . 0 7} \beta$ & $0.75 \pm 0.06$ & $0.71 \pm 0.07$ & $0.79 \pm 0.07$ & $0.56 \pm 0.03 £$ \\
\hline $\begin{array}{l}\text { * - } p<0,05 \text { between befo } \\
\#-p<0,05 \text { between bef } \\
\$-p<0,05 \text { between befo } \\
€-p<0,05 \text { between bef } \\
€ \text { - } p<0,05 \text { between afte } \\
\text { C - } p<0,05 \text { between nel } \\
\mu \text { - } p<0,05 \text { between ate } \\
\beta-p<0,05 \text { between ate } \\
\alpha-p<0,05 \text { between ate }\end{array}$ & $\begin{array}{l}\text { and after tre } \\
\text { e and after tr } \\
\text { and after tre } \\
\text { and after tre } \\
\text { treatment car } \\
\text { olol and biso } \\
\text { lol and bisop } \\
\text { lol and carve } \\
\text { lol and nebiv }\end{array}$ & $\begin{array}{l}\text { ment in atenol } \\
\text { tment in carved } \\
\text { ment in bisopr } \\
\text { tment in nebivo } \\
\text { dilol and bisop } \\
\text { olol group afte } \\
\text { lol group after } \\
\text { ilol group after } \\
\text { ol group after } t\end{array}$ & $\begin{array}{l}\text { ol group } \\
\text { dilol group } \\
\text { olol group } \\
\text { lol group } \\
\text { rolol group } \\
\text { r treatment } \\
\text { treatment } \\
\text { treatment } \\
\text { reatment }\end{array}$ & & & & & \\
\hline
\end{tabular}

Glucose levels in the atenolol group increased at all three points of PHTT. Increased fasting insulin level is a sign of the progression of insulin resistance in group of atenolol. The percentage of patients with identified insulin resistance (HOMA> 3) increased from $34.4 \%$ to $71.9 \%$ ( $p<0.05)$ six months following treatment. According to PHTT Score there were 6 (18.7\%) cases of onset diabetes. Carvedilol therapy contributed to a significant, reduction in fasting insulin. In comparison to baseline data fasting insulin levels decreased by $22.8 \%(\mathrm{p}<0.05)$, HOMA index 
by $21.7 \%(\mathrm{p}<0.05)$, and serum glucose levels did not change significantly. The percentage of patients whose HOMA index was 3 and above decreased from $31.3 \%$ to $18.8 \%$. In the carvedilol group, there were 2 with onset diabetes (6.3\%). Bisoprolol based treatment significantly decreased HOMA index by $17.4 \%$ (p $<0.05)$, fasting insulin by $10.7 \%(\mathrm{p}<0.05)$, fasting glucose by $10 \%$ $(\mathrm{p}<0.05)$. This group also demonstrated a positive trend toward HOMA index $>3$ (at baseline $-34.4 \%$ of patients at the end of

Table 4 :Dynamics of HOMA, insulin and glucose level during treatment in groups

\begin{tabular}{|c|c|c|c|c|c|c|c|c|}
\hline & \multicolumn{4}{|c|}{ Before treatment } & \multicolumn{4}{|l|}{ After treatment } \\
\hline & Atenolol (n=32) & $\begin{array}{l}\text { Carvedilol } \\
(\mathrm{n}=32)\end{array}$ & $\begin{array}{l}\text { Bisoprolol } \\
(\mathrm{n}=32)\end{array}$ & $\begin{array}{l}\text { Nebivolol } \\
(\mathrm{n}=35)\end{array}$ & Atenolol (n=32) & $\begin{array}{l}\text { Carvedilol } \\
(\mathrm{n}=32)\end{array}$ & Bisoprolol (n=32) & $\begin{array}{l}\text { Nebivolol } \\
(n=35)\end{array}$ \\
\hline HOMA index. units & $2.30 \pm 0.26$ & $2.34 \pm 0.23$ & $\begin{array}{l}2.33 \pm \\
0.33\end{array}$ & $2.29 \pm 0.21$ & $4.31 \pm 0.53^{*}$ & $\begin{array}{l}1.77 \pm \\
0.19 \# €\end{array}$ & $1.88 \pm 0.16 \mu$ & $1.76 \pm 0.10 £($ \\
\hline $\begin{array}{l}\text { Fasting glucose. } \\
\mathrm{mmol} / \mathrm{l}\end{array}$ & $5.48 \pm 0.16$ & $5.65 \pm 0.15$ & $\begin{array}{l}5.46 \pm \\
0.14\end{array}$ & $5.39 \pm 0.10$ & $5.81 \pm 0.20$ & $5.55 \pm 0.18$ & $5.03 \pm 0.13 \$ \mu$ & $5.00 \pm 0.10 £(C$ \\
\hline Glucose $1 \mathrm{hr} . \mathrm{mmol} / \mathrm{l}$ & $7.90 \pm 0.39$ & $8.30 \pm 0.39$ & $\begin{array}{l}7.74 \pm \\
0.35\end{array}$ & $7.79 \pm 0.25$ & $10.17 \pm 1.43$ & $8.03 \pm 0.49$ & $10.14 \pm 3.03$ & $7.00 \pm 0.25 £(C$ \\
\hline Glucose $2 \mathrm{hr} . \mathrm{mmol} / \mathrm{l}$ & $6.13 \pm 0.36$ & $6.34 \pm 0.43$ & $\begin{array}{l}6.31 \pm \\
0.31\end{array}$ & $6.07 \pm 0.30$ & $7.45 \pm 0.63^{*}$ & $6.35 \pm 0.48$ & $5.66 \pm 0.21 \mu$ & $5.86 \pm 0.31 \subset$ \\
\hline $\begin{array}{l}\text { Fasting insulin. } \\
\mathrm{mkED} / \mathrm{ml}\end{array}$ & $9.30 \pm 1.05$ & $9.24 \pm 0.81$ & $\begin{array}{l}9.26 \pm \\
1.26\end{array}$ & $9.16 \pm 0.95$ & $16.62 \pm 1.85^{*}$ & $\begin{array}{l}7.09 \pm \\
0.74 \# €\end{array}$ & $8.25 \pm 0.69 \mu$ & $7.73 \pm 0.60 \odot$ \\
\hline $\begin{array}{l}\text { Insulin } 1 \text { hr. mkED/ } \\
\text { ml }\end{array}$ & $63.13 \pm 9.93$ & $\begin{array}{l}55.63 \pm \\
5.47\end{array}$ & $\begin{array}{l}53.37 \\
\pm 7.82\end{array}$ & $\begin{array}{l}52.41 \\
\pm 4.87\end{array}$ & $76.46 \pm 8.71^{*}$ & $\begin{array}{l}47.89 \pm \\
4.32 €\end{array}$ & $40.84 \pm 5.23 \mu$ & $48.40 \pm 6.47 \Subset$ \\
\hline $\begin{array}{l}\text { Insulin } 2 \text { hr. mkED/ } \\
\text { ml }\end{array}$ & $39.76 \pm 9.67$ & $\begin{array}{l}24.77 \pm \\
3.43\end{array}$ & $\begin{array}{l}31.23 \\
\pm 5.72\end{array}$ & $\begin{array}{l}26.83 \\
\pm 2.99\end{array}$ & $52.66 \pm 13.48$ & $27.83 \pm 5.55$ & $21.51 \pm 4.68 \mu$ & $23.46 \pm 2.76$ \\
\hline $\begin{array}{l}\text { Area under the curve } \\
\text { for glucose mmol/l/ } \\
\mathrm{hr}\end{array}$ & $13.70 \pm 0.58$ & $\begin{array}{l}14.29 \pm \\
0.60\end{array}$ & $\begin{array}{l}13.63 \pm \\
0.48\end{array}$ & $13.42 \pm 0.40$ & $16.80 \pm 1.76$ & $\begin{array}{l}13.98 \pm \\
0.77\end{array}$ & $15.49 \pm 3.09$ & $12.50 \pm 0.43 \odot$ \\
\hline $\begin{array}{l}\text { Area under the curve } \\
\text { for insulin mkED/ } \\
\mathrm{ml} / \mathrm{hr}\end{array}$ & $87.66 \pm 14.77$ & $\begin{array}{l}72.63 \pm \\
6.78\end{array}$ & $\begin{array}{l}73.62 \pm \\
8.44\end{array}$ & $\begin{array}{l}70.43 \pm \\
5.05\end{array}$ & $111.10 \pm 14.42 *$ & $\begin{array}{l}65.35 \pm \\
6.64 €\end{array}$ & $55.72 \pm 7.05 \mu$ & $63.99 \pm 6.52 \Subset$ \\
\hline \multicolumn{9}{|c|}{ * - $p<0.05$ between before and after treatment in atenolol group } \\
\hline \multicolumn{9}{|c|}{$£-p<0.05$ between before and after treatment in nebivolol group } \\
\hline \multicolumn{9}{|c|}{$€-\mathrm{p}<0.05$ between atenolol and carvedilol group after treatment } \\
\hline \multicolumn{9}{|c|}{ (C) - $p<0.05$ between atenolol and nebivolol group after treatment } \\
\hline \multicolumn{9}{|c|}{$\mu-\mathrm{p}<0.05$ between atenolol and bisoprolol group after treatment } \\
\hline No diferens after treat & nent between nebi & lol. carvedilo & bisoprolol & oups & & & & \\
\hline
\end{tabular}

We analyzed the influence of atenolol on carbohydrate metabolism depending on the addition of hydrochlorothiazide. Both atenolol monotherapy and in adding HCTZ worsened all glucose values and insulin and HOMA for oral glucose tolerance test, but there was significantly greater deterioration of adding HCTZ. Thus, fasting glucose levels in atenolol monotherapy subgroup decreased from $5,4 \pm 0,2$ to $5,3 \pm 0,1 \mathrm{mmol} / \mathrm{l}(\mathrm{p}<0.05)$, while adding HCTZ increased from $5,8 \pm 0,3$ to $7,0 \pm 0,4 \mathrm{mmol} / \mathrm{l}$ ( $p<0.05$ ), the difference between subgroups was significant, $p$ $<0.05$. Fasting insulin levels also increased significantly in the the study - 12.5\%). There was also one case of the onset diabetes (3.2\%). In the nebivolol group the HOMA index decreased from $2.3 \pm 0.3$ to $1.76 \pm 0.1 \mathrm{mmol} / \mathrm{l}(\mathrm{p}<0.05)$, and fasting glucose decreased by $7.4 \%(\mathrm{p}<0.05)$; no cases of onset diabetes were recorded. The proportion of patients with manifest insulin resistance decreased from $34.3 \%$ to $2.9 \%$ ( $p<0.05$ ). This finding suggests that nebivolol may improve insulin sensitivity (Table 4). 
we can conclude that adherence to HCTZ monotherapy with atenolol is accurate negative impact on carbohydrate metabolism and the use of such combinations may be considered undesirable in patients with hypertension and clinical signs of metabolic syndrome. We noticed a significant difference in the incidence of cases of diabetes in the two groups of patients. All cases of diabetes were in the group with HCTZ. Diabetes appeared in 5 patients, predominantly in patients with diagnosed insulin resistance at baseline or in violation of tolerance to carbohydrates. That is to say that diabetes develops in patients with insulin resistance mainly due to hyperinsulinemia. Due to the impact on insulin resistance we can help to reduce onset of diabetes.

After analyzing the effects of carvedilol on carbohydrate metabolism depending with the addition of hydrochlorothiazide, we found that in group carvedilol alone, most of the glucose and insulin oral glucose tolerance test level significantly improved, while as adding HCTZ. Thus, fasting glucose alone in the carvedilol subgroup did not change $(5,6 \pm 0,2$ to $5,5 \pm$ $0,2 \mathrm{mmol} / \mathrm{l}, \mathrm{p}>0.05$ ), while adding HCTZ decreased it more $(5,9 \pm 0,3$ to $5,6 \pm 0,2 \mathrm{mmol} / \mathrm{l}, \mathrm{p}<0.05)$, the difference between subgroups was significant, $\mathrm{p}<0.05$. Fasting insulin levels were significantly decreased in subgroup of carvedilol monotherapy $9,2 \pm 0,9$ to $6,9 \pm 0,8 \mathrm{mked} / \mathrm{ml}(\mathrm{p}<0.05)$, and the addition of HCTZ $9,4 \pm 1,8$ to $7,5 \pm 1,6$, mked/ml, $(p<0.05)$, this difference between subgroups was significant, $p<0.05$. HOMA index was significantly decreased in both carvedilol monotherapy and the addition of HCTZ subgroups. So, HOMA index in subgroup of carvedilol monotherapy decreased from $2,2 \pm 0,2$ to $1,7 \pm 0,2 \mathrm{U}$, $(\mathrm{p}<0.05)$ and in the subgroup with HCTZ from $2,6 \pm 0,6$ to $1,9 \pm$ $0,4 \mathrm{U}(\mathrm{P}>0.05)$ difference between subgroups was significant, $p$ $<0.05$. Thus, we can conclude that monotherapy with carvedilol has statistically significant effects on carbohydrate metabolism, and addicting HCTZ had not significantly impaired carbohydrate metabolism, so the use of this combination may be considered appropriate in patients with hypertension and clinical signs of metabolic syndrome. We noted significant negative impact of the addition of HCTZ incidence of cases of diabetes in these two groups of patients. In the group with diagnosed diabetes HCTZ not occurred in the subgroup without diabetes HCTZ appeared in two patients diagnosed with insulin resistance at baseline. In other words, we can say that the addition of HCTZ monotherapy to carvedilol did not contribute to the onset of diabetes and its appearance is connected, likely with the matter of disease itself.

During the analysis of the effect of bisoprolol on carbohydrate metabolism depending on the addition of hydrochlorothiazide, we found that in group of bisoprolol alone almost all levels of glucose and insulin in oral glucose tolerance test, but not the glucose level san hour after test and glucose area, was significantly improved, while in group addition of HCTZ significant positive dynamics was observed not in all points of oral glucose tolerance test. Thus, the observed increasing fasting insulin levels with the adding of HCTZ (from 6,8 $\pm 1,2$ to $9,2 \pm 1,4 \mathrm{mmol} / \mathrm{l}, \mathrm{p}<0.05$ ), fasting insulin in group of bisoprolol monotherapy significantly decreased from $10,4 \pm 1,7$ to $7,8 \pm 0,8$ $\mathrm{mmol} / \mathrm{l}(\mathrm{p}<0.05)$, the difference between subgroups significant, $\mathrm{p}<0.05$. Fasting glucose was significantly decreased in both subgroups: in patients with bisoprolol monotherapy $5,5 \pm 0,2$ to $5,0 \pm 0,1 \mathrm{mked} / \mathrm{ml}(\mathrm{p}<0.05)$, while adding HCTZ $5,4 \pm 0,3$ to $5,1 \pm 0,3 \mathrm{mked} / \mathrm{ml}(\mathrm{p}<0.05)$, the difference between groups not significant, $\mathrm{p}>0.05$. HOMA index was significantly decreased in the subgroup of bisoprolol monotherapy $2,6 \pm 0,5$ to $1,8 \pm 0,2 \mathrm{U}$, $(\mathrm{p}<0.05)$ and in the group with HCTZ increased from $1,7 \pm 0,4$ to 2 $1 \pm 0,3 \mathrm{U},(\mathrm{p}<0.05)$, the difference between groups not significant, $\mathrm{p}>0.05$. Thus, we can conclude that bisoprolol monotherapy hada statistically significant effect on carbohydrate metabolism.

Combination therapy with HCTZ in contrast had a negative effect on carbohydrate metabolism. We found one case of onset diabetes in subgroup of bisoprolol with HCTZ. Therefore, the use of such combinations may be considered inappropriate in patients with hypertension and clinical signs of metabolic syndrome.

After analyzing the effect of nebivolol on parameters of carbohydrate metabolism depending on the addition of hydrochlorothiazide, we found that with the nebivolol monotherapy all indicators of glucose and insulin in oral glucose tolerance test significantly improved, while adding HCTZ this positive trend was less pronounced. Thus, fasting glucose levels in the nebivolol monotherapy group decreased from $5,5 \pm 0,2$ to $5,1 \pm 0,1 \mathrm{mmol} / \mathrm{l}(\mathrm{p}<0.05)$, and in case of adding HCTZ this figure has not changed, the difference between groups significant, $\mathrm{p}<$ 0,001 . Fasting insulin was significantly decreased in patients in nebivolol monotherapy group 9,7 $\pm 0,4$ to $7,8 \pm 0,8 \mathrm{mked} / \mathrm{ml}$ (p $<0.05$ ), but not significantly increased when HCTZ was added, the difference between groups was significant, $p<0.05$. HOMA index was significantly decreased in the nebivolol monotherapy group, while adding HCTZ did not change it. So, HOMA index in the nebivolol monotherapy group decreased from $2,5 \pm 0,4$ to $1,8 \pm 0,2 \mathrm{U},(\mathrm{p}<0.05)$ difference between groups is significant, $p<0.05$. Thus, we can conclude that nebivolol monotherapy has statistically significant effects on carbohydrate metabolism, and the addition of HCTZ does not significantly impair carbohydrate metabolism, so the use of this combination may be considered appropriate in patients with hypertension and clinical signs of metabolic syndrome. Onset diabetes did not appear in any groups.

HCTZ in combination with atenolol led to significantly worsened glycemic profiles and increased insulin resistance compared to the subgroup without HCTZ. Administration of HCTZ with nebivolol and carvedilol had no negative impact on the state of insulin resistance. In the carvedilol group the adverse metabolic effect of adding HCTZ neutralized the positive impact of carvedilol (HOMA were not significantly changed). Nebivolol therapy with or without HCTZ decreased HOMA index consistently. Monotherapy with bisoprolol had a significant impact on carbohydrate metabolism. Combination therapy with HCTZ conversely negatively impacted carbohydrate metabolism. There was one case of onset diabetes in the bisoprolol with HCTZ group. Therefore, the use of such combinations may be considered inappropriate in patients with hypertension and clinical signs of metabolic syndrome. 
We analyzed in the subgroup of patients depended of HOMA level. Results presents in (Table 5), In the atenolol subgroup with HOMA $>3$ was significant worsening fasting insulin and HOMA index, $(\mathrm{p}<0,05)$. In the atenolol subgroup with HOMA $<3$, all indicators significant demonstrated worsening of glycemic profile. (Table 5).

During treatment with carvedilol significant decreased in patients with levels of HOMA> 3 fasting insulin level, $(\mathrm{p}<0.05)$ and HOMA index. In the carvedilol subgroup with HOMA $<3$ was the decreased fasting insulin and HOMA index, $(\mathrm{p}<0.05)$ (Table $5)$.

In the bisoprolol there were positive changes in the subgroup of patients with HOMA $>3$. Fasting insulin and fasting glucose, HOMA index significant decreased, $(p<0,05)$. In the subgroup with HOMA $<3$ increased fasting insulin and HOMA index, $(\mathrm{p}<0.05)$ (Table 5).




In the nebivolol treatment in subgroup HOMA $>3$ was improvement fasting insulin, fasting glucose and HOMA index, $(\mathrm{p}<0,05)$. In subgroup $\mathrm{HOMA}<3$ was significant improvement area under curve for insulin, ( $p<0.05$ ), but HOMA index and fasting insulin, fasting glucose not significant changed (Table 5).General properties of 4 beta-blockers are presented in Table 6.

\begin{tabular}{|l|l|l|l|l|}
\hline \multicolumn{4}{|l|}{ Table 6: Properties of beta-blockers } \\
\hline Factor & Atenolol & Bisoprolol & Carvedilol & Nebivolol \\
\hline $\begin{array}{l}\beta \text {-blockade } \\
\text { potency ratio }\end{array}$ & ++ & + & + & + \\
\hline$\beta 1 / \beta 2$ selectivity & ++ & +++ & - & ++++ \\
\hline $\begin{array}{l}\text { intrinsic } \\
\text { sympathomimetic } \\
\text { activity (ISA). }\end{array}$ & - & - & - & - \\
\hline $\begin{array}{l}\text { drug half life } \\
\text { metabolic effects }\end{array}$ & $\begin{array}{l}\text { Negative } \backslash \\
\text { neutral }\end{array}$ & Neutral & $\begin{array}{l}\text { Positive } \backslash \\
\text { neutral }\end{array}$ & $\begin{array}{l}\text { Positive } \backslash \\
\text { neutral }\end{array}$ \\
\hline $\begin{array}{l}\text { vasodilation } \\
\text { effects }\end{array}$ & - & 0 & + & ++ \\
\hline
\end{tabular}

\section{Discussion}

We can conclude that during atenolol based treatment risk of developing type 2 diabetes increased significantly, while nebivolol and carvedilol therapy significantly improved glycemic profile, which may improve prognosis. Thus, nebivolol and carvedilol may be recommending as a drug of choice in patients with hypertension and metabolic syndrome with signs of impaired carbohydrate metabolism.

Administration of nebivolol as monotherapy or combination with diuretics may be rational in patients with mild to moderate hypertension, clinical signs of metabolic syndrome and manifestations of insulin resistance without diabetes. Bisoprolol can be used as metabolically neutral drugs in patients with mild to moderate hypertension, clinical signs of metabolic syndrome and manifestations of insulin resistance without diabetes. Administration of atenolol is undesirable in patients with hypertension, clinical signs of metabolic syndrome without diabetes despite of the presence or absence manifestations of insulin resistance because it appears to facilitate the development of diabetes.

The LIFE trial (Lozartan Intervention For Endpoint reduction in hypertension) long-term use of selective betablocker atenolol (over 4 years) in patients with hypertension has led to the development of type 2 diabetes de novo only in $8 \%$ of patients, it is 3.5 times lower than in ARIC study (28\%), in which first generation nonselective beta-blocker without vasodilating activity(propranolol) was used, since research began in the $80 \mathrm{~s}$ when the range of selective beta-blockers was not so great [12].

It was found that the pro diabetic effect of beta-blockers in most cases is present due to the properties of non-selective beta-blockers amplify tissue insulin resistance. At the same time, according to the purpose of the analysis Jasob et al (1998), which combines a number of studies on treatment of hypertension with the use of beta-blockers, it appears that some of them may even increase the sensitivity of peripheral tissues to insulin [6].

Among the drugs that significantly improved insulin sensitivity (which was assessed by HOMA index), beta-blockers appeared, including not selective to $\beta$ - adrenergic receptors, but which had a vasodilator activity and property to block $\alpha 1$-and $\alpha 2$ - adrenergic receptors ( Carvedilol, celiprolol, dilevalol). Perhaps vasodilatation and related simplified insulin delivery to the tissues is of great importance in elimination of insulin resistance than $\beta$ - selectivity of beta-blockers [1].

Nebivolol not only affects the $\beta-2$ adrenergic receptors, but also able to modulate the release endoteliy relaxation factor - nitric oxide (NO) causing a decrease in peripheral resistance. Nebivolol therapy almost does not effect on glucose metabolism. In the placebo controlled study therapy $5 \mathrm{mg}$ nebivolol, which was administered for 4-8 weeks did not lead to changes in plasma glucose levels in patients with hypertension and without diabetes. In patients with impaired glucose tolerance nebivolol (2.5 and 5 $\mathrm{mg}$ ) did not change it, and atenolol (50 and $100 \mathrm{mg}$ ) resulted in a significant decrease in sensitivity to insulin, compared with placebo. It was significantly decreased glucose clearance value in the atenolol group. In 30 patients suffering from hypertension and insulinfree diabetes, for 24 weeks nither nebivolol (5 mg), nor atenolol (50 mg) did not affect the utilization of glucose and insulin sensitivity $[10,14,15,20]$.

In most studies, including a 6-month follow-up of patients with insulin free diabetes in patients with hypertension nebivolol had no effect on total cholesterol, high and low density lipoproteins, triglycerides, apolipoproteins A1 and B. Moreover, Y. Lacourciere and co-authors showed that total cholesterol levels and low density lipoprotein with the nebivolol had even decreased [9].

In the mid-80s in the global pharmaceutical market was Carvedilol - a new drug for the treatment of hypertension. The results of numerous studies suggest that this drug used in therapeutic doses acts as a nonselective b-blocker and a-adrenergic receptors blocker. The benefit of carvedilol in that it does not cause severe bradycardia, which is inherent in selective blocker b - blockers, and tachycardia, which is typical of vasodilators. Since the mid-90th the new perspectives of effective clinical use of carvedilol appeared $[16,17]$.

The main mechanisms of action of carvedilol should be noted: blocking the renin - angiotensin system, sympathetic division of the autonomic nervous system, endothelin system; reducing the total peripheral vascular resistance and reduction of preload; reduce myocardial oxygen demand; lack of reflex tachycardia; inhibition of cardiac arrhythmias; inhibition of cardiomyocyte apoptosis; inhibition of proliferation of smooth muscle cells; inhibition of the formation of free radicals; slowing the progression of heart failure.

In the recent literature there are many reports of the obtained clinical evidence that have shown the positive metabolic effects of carvedilol. Thus, within 24 weeks of observation 
carvedilol $50 \mathrm{mg}$ daily had a positive effect on blood glucose and fasting insulin levels compared with atenolol $100 \mathrm{mg}$ daily in patients with obesity, hypertension and type II diabetes, while body weight of these patients remained constant. Lipid spectrum, especially triglycerides, cholesterol and high density lipoprotein levels have also been upgraded by the end of the observation [ 1 , $3]$.

GEMINI trial (The Glycemic Effects in Diabetes Mellitus: Carvedilol-Metoprolol Comparison in Hypertensives). In this randomized, double-blind study (G. Bakris et al, 2004) it was made a comparison of two beta - blockers in the treatment regimen of patients with hypertension and type 2 diabetes: metoprolol $\beta 1$ - selective beta - blocker and carvedilol - nonselective beta blocker, which has an additional feature to block $\alpha 1$ - adrenergic receptors [1].

Researchers believed that due to the $\alpha 1$ - adrenergic receptors blockade carvedilol may have advantages over metoprolol not only due to its already proven vasodilating activity, but perhaps due to more favorable effects on metabolic parameters (dyslipidemia, insulin resistance), due to that the $\alpha 1$ - adrenergic receptors blockade promotes increased activity of lipoprotein lipase, which breaks down triglycerides. The study included 1235 patients with hypertension and diabetes mellitus type 2 . One group $(n=737)$ received metoprolol tartrat $50-200 \mathrm{mg}$ twice a day, the second one $(\mathrm{n}=498)$ - carvedilol 6,25-25 mg twice a day for 35 weeks. Moreover, all patients continued to receive previously prescribed therapy. Comparing data of glycemic control it was recorded that during carvedilol treatment mean level of hba1c in this group did not change, and in metoprolol group it increased by $0.15 \%$, insulin sensitivity (which is determined by the HOMA index) improved in carvedilol group, but did not changed in metoprolol group (decreased by 9.1 and $2.0 \%$, respectively). The risk of microalbuminuria was significantly lower in carvedilol group than in metoprolol group (6.4 and $10.3 \%$, respectively) $[4,7,11]$.

Thus, this study dispelled the "myth" about the dangers of beta - blockers in treatment patients with diabetes and proved that carvedilol not only worsens metabolic control in this case, but even improves insulin sensitivity. Of course, the results of this study cannot be transferred to the whole group of beta-blockers because carvedilol has additional properties of $\alpha 1$ - blocker, which explains these obtained metabolic effects.

In numerous clinical studies the effectiveness of bisoprolol without any adverse effects on insulin sensitivity and glucose metabolism during long-term treatment of patients with hypertension and diabetes was confirmed. Thus, the usage of bisoprolol 5-10 mg daily for 24 weeks did not significantly differedcompared with previous figures according to the levels of plasma glucose, gly cosylated hemoglobin and plasma insulin after glucose load, at the same time the levels of systolic, diastolic and mean blood pressure decreased significantly.

HU Janka et al. Had investigated the effect of bisoprolol on blood glucose levels in patients with type 2 diabetes. After 2 weeks of bisoprolol therapy blood glucose levels 2 hours after taking the drug or placebo were evaluated, it was found a significant difference in this glucose levels between bisoprolol and placebo groups. These data allowed the authors to conclude that there were no episodes of hypoglycemia observed during bisoprolol treatment of patients with diabetes so there is no need of dose adjustment of oral antidiabetic drugs [7].

So the representatives of only a one class of antihypertensive drugs potentially may have different effects on glycemia in patients with metabolic syndrome.

\section{Conclusions}

This study showed that all four beta-blockers had similar BP lowering but different metabolic effects. There was a significant worsening of insulin resistance in patients receiving atenolol. Bisoprolol can be used as metabolically neutral drugs in patients with mild to moderate hypertension, clinical signs of metabolic syndrome and manifestations of insulin resistance without diabetes. Patients treated with nebivolol and carvedilol had a trend toward more improvement in insulin sensitivity and glucose tolerance. Nebivolol and carvedilol therapy significantly improved glycemic profile, which may improve prognosis. Nebivolol and carvedilol may be recommend as a drug of choice in patients with hypertension and metabolic syndrome with signs of impaired carbohydrate metabolism.

\section{References}

1. Bakris GL, Fonseca V, Katholi RE, McGill JB, Messerli FH, Phillips RA, et al. Metabolic effects of carvedilol vs metoprolol in patients with type 2 diabetes mellitus and hypertension. JAMA. 2004;292(18):2227-2236. Doi: 10.1001/jama.292.18.2227

2. Celik T, Iyisoy A, Kursaklioglu H, Kardesoglu E, Kilic S, Turhan H,et al. Comparative effects of nebivolol and metoprolol on oxidative stress, insulin resistance, plasma adiponectin and soluble P-selectin levels in hypertensive patients J. Hypertens. 2006;24(3):591-596. DOI:10.1097/01.hjh.0000209993.26057.de

3. Dekker JM, Girman C, Rhodes T, Nijpels G, Stehouwer CD, Bouter LM, et al. Metabolic Syndrome and 10-year cardiovascular disease risk in the Hoorn study Circulation. 2005;112(5):666-673. DOI: 10.1161/ CIRCULATIONAHA.104.516948

4. Fogari R, Zoppi A, Corradi L, Preti P, Mugellini A, Lusardi P. Beta-blocker effects on plasma lipids during prolonged treatment of hypertensive patients with hypercholesterolemia. J. Cardiovasc Pharmacol. 1999;33(4):534-539.

5. Fogari R, Zoppi A, Lazzari P, Mugellini A, Lusardi P, Preti P, et al. Comparative effects of nebivolol and atenolol on blood pressure and insulin sensitivity in hypertensive subjects with type II diabetes. J Hum Hypertens. 1997;11(11):753-757.

6. Jacob S, Rett K, Henriksen EJ. Antihypertensive therapy and insulin sensitivity: do we have to redefine the role of beta-blocking agents Am J Hypertens. 1998;11(10):1258 - 1265.

7. Janka HU. Insulin therapy in elderly patients with type 2 diabetes: the role of insulin glargine Diabetes Obes Metab. 2008;10(Suppl 2):35-41. Doi: 10.1111/j.1463-1326.2008.00843.x.

8. National Institutes of Health: Third Report of the National Cholesterol Education Program Expert Panel on Detection, Evaluation, and Treatment of High Blood Cholesterol in Adults (Adult Treatment Panel 
III). Washington, DC, US Govt. Printing Office, 2001 (NIH publ. no. 013670)

9. Nebivolol. The first highly selective [1-blocker with NO (nitric oxide) modulating properties Nebivolol monograph. - London: Churchill Communications Europe, 1996;:63.

10. Nodari S, Metra M, Dei Cas L. Beta blocker treatment of the patient with diastolic heart failure and arterial hypertension. A prospective, randomized comparison of the long-term effects of atenolol versus nebivolol. Eur. J. Fail. 2003;5(5):621-627.

11. Nuttall S.L, Routledge HC, Kendall MJ. A comparison of the beta1selectivity of three beta1-selective beta-blockers. J Clin Pharm Ther 2003;28(3):179-186

12. Okin PM, Hille DA, Wiik BP, Kjeldsen SE, Lindholm LH, Dahlöf B, et al. In-treatment HDL cholesterol levels and development of new diabetes mellitus in hypertensive patients: the LIFE Study. Diabet Med. 2013;30(10):1189-1197. Doi:10.1111/dme.12213.

13. Reaven GM, Lithell $\mathrm{H}$, Landsberg L. Hypertension and associated metabolic abnormalities: the role of insulin resistance and the sympathoadrenal system. NEngl JMed . 1996;334(6):374-381. Doi: 10.1056/NEJM199602083340607

14. Rizos E, Bairaktari E, Kostoula A, Hasiotis G, Achimastos A, Ganotakis $\mathrm{E}$, et al. The combination of nebivolol plus pravastatin is associated with a more beneficial metabolic profile compared to that atenolol plus pravastatin in hypertensive patients with dyslipidemia: a pilot study. JCardiovasc Pharmacol Ther. 2003;8(2):127-134. Doi: $10.1177 / 107424840300800206$
15. Rosei EA, Rizzoni D. Metabolic profile of nebivolol, a betaadrenoreceptor antagonist with unique characteristics. Drugs. 2007;67:1097 - 1107.

16. Stoschitzky K, Stoschitzky G, Brussee H, Bonelli C, Dobnig H. Comparing beta blocking effects of bisoprolol, carvedilol and nebivolol. Cardiology. 2006;106(4):199-206.

17. Lakka HM, Laaksonen DE, Lakka TA, Niskanen LK, Kumpusalo E, Tuomilehto J. The Metabolic Syndrome and Total and Cardiovascular Disease Mortality in Middle-aged Men. JMMA. 2002;288(21):27092716.

18. Tschritter O, Fritsche A, Shirkavand F, Machicao F, Häring H, Stumvoll M. Assessing the Shape of the Glucose Curve During an Oral Glucose Tolerance Test. Diabetes Care. 2003;26(4):1026-1033.

19. Unzueta Montoya A, Unzueta A Jr, Ordonez Toquero G, Villasis Keever MA, Cocoletzi López J, Medina Santillán R. Comparative study between bisoprolol and metoprolol, combined with hydrochlorothiazide, as antihypertensive therapy Arch Inst Cardiol Mex. 2000;70(6):589-595.

20.Van Nueten L, Taylor FR, Robertson JI. Nebivolol vs. atenolol and placebo in essential hypertension: a double-blind randomized trial. J Hum Hypertens. 1998; 12(2):135-140.

21.Vulpis V, Antonacci A, Prandi P, Bokor D, Pirrelli A. The effects of bisoprolol and atenolol on glucose metabolism in hypertensive patients with non-insulin-dependent diabetes mellitus Minerva Med. 1991;82(4):189-193. 